\title{
Implementing Green Infrastructure and Ecological Networks in Europe: Lessons Learned and Future Perspectives
}

\author{
K. Čivic ${ }^{1}$ and L. M. Jones-Walters ${ }^{2}$ \\ ${ }^{1}$ ECNC-European Centre for Nature Conservation, Reitseplein 3, PO Box 90154, \\ $5000 L G$ Tilburg, the Netherlands \\ ${ }^{2}$ Alterra, Wageningen UR, Wageningen Campus, 6700 AA Wageningen, the \\ Netherlands \\ Corresponding Authors: civic@ecnc.org; lawrence.jones-walters@wur.nl
}

Received 4 July 2014; Accepted 27 November 2014;

Publication 19 March 2015

\begin{abstract}
The impact of landscape fragmentation is well recognised as one of the key contributors to the past and present decline in European wildlife. Ecological networks were seen as a solution to this problem and have been the subject of research, policy and practice for nearly 40 years; resulting in many examples of best practice and lessons learned. More recently the European Commission has introduced the concept of Green Infrastructure (GI) which retains the frame work of ecological networks at its core but which offers a more sophisticated integration of economic and social factors and the delivery of a range of ecosystem services. GI has already been included as a concept in EU strategy and offers much for future policy making and delivery of sectoral integration. The views of stakeholders indicate that there a number of key areas for improvement but confirm the potential of the concept. Further work should consider the practicalities of the full translation of the protected area networks into functional ecological networks and making them integral building blocks of the green infrastructure both at the level of policy and practice. In addition information about how to create actual ecological
\end{abstract}

Journal of Green Engineering, Vol. 4, 307-324.

doi: 10.13052/jge1904-4720.444

(c) 2014 River Publishers. All rights reserved. 
networks at the delivery level, particularly where this has involved stakeholder and public participation needs to be researched and made widely available. The issue of communication; specifically to politicians and decision makers within key sectors (such as spatial planning, transport, industry, etc.) but more widely to researchers, conservation practitioners, businesses and the interested public remain to be fully addressed. [1]

Keywords: ecological networks, green infrastructure, ecosystem services, climate change, resource efficiency, innovation.

\section{Introduction}

Landscape fragmentation by human activities and infrastructure is a major cause of the well recorded decrease in many European wildlife populations. The current trend of steadily increasing landscape fragmentation contradicts the principle of sustainability and there is a clear and urgent need for action. The continuing proliferation of urban development and transport infrastructure is likely to cause a significant increase in the already existing problems. This increase is likely to be significant, not least because many of the ecological effects of the current levels of fragmentation have yet to manifest fully [2].

Ecological networks represent a very effective tool for combating the effects of fragmentation by: counteracting fragmentation; conserving and buffering core areas; maintaining and establishing ecological connectivity; being a tool for ecological design and planning; being a tool for interaction with other land uses; being an important political instrument. A lot of work has been done in relation to implementing the ecological networks in Europe at various levels with the Pan European Ecological Network (PEEN) as an umbrella initiative. The PEEN approach was successful in reaching its goal of promoting the idea of a pan-European vision of biodiversity conservation through a European ecological network [3]. It is a genuine framework for strategic cooperation and a useful tool for international cooperation, providing all European countries with a single and flexible monitoring and coordination mechanism [4]. In addition, under Article 10 of the Habitats Directive [5], which is one of the cornerstones of European nature legislation, provides "a specific contribution to a coherent European ecological network of protected sites" by designating Special Areas of Conservation (SACs) for habitats listed on Annex I and for species listed on Annex II. These measures are also to be applied to Special Protection Areas (SPAs) classified under Article 4 of the Birds Directive [6]. Currently, ecological networks are taken up as 
integral parts of Green Infrastructure (GI)- an approach and a new policy tool combining nature conservation and sustainable development promoted by the European Commission [7].

Ecological connectivity remains a priority for international biodiversity conservation policy; illustrated by Target 11 of the Aichi Biodiversity Targets, signed at COP 10 of the Convention on Biological Diversity (CBD) in 2010, which states that: "By 2020, at least 17 per cent of terrestrial and inland water areas and 10 per cent of coastal and marine areas, especially areas of particular importance for biodiversity and ecosystem services, are conserved through effectively and equitably managed, ecologically representative and well-connected systems of protected areas and other effective areabased conservation measures, and integrated into the wider landscape and seascape" [8].

As a response to the Aichi targets, (and therefore included in the European Commission's EU 2020 European biodiversity headline target and 2050 vision whose aim is to halt and reverse the loss of biodiversity across the EU territory of the member states) [9], the GI initiative has relatively recently been launched as a new concept, to coincide with the adoption by the Commission of the GI Strategy, and has the potential to become an important policy instrument [10]. This has been reiterated and further reinforced by the 'Pan-European 2020 Strategy for Biodiversity' adopted by the Council for the Pan-European Biological and Landscape Diversity Strategy (PEBLDS), for the wider PanEuropean region [11].

In the context of these developments it is important to reflect on what have we learned from the work carried out previously (over the past four decades) on the development and implementation of ecological networks at various levels (from the pan-European, supra-national, national, regional and local) across Europe and elsewhere; how to best utilise and put into practice the lessons learned; and how to ensure that the GI initiative takes a necessary step beyond what has already been achieved.

This paper provides a summary of the achievements of work that has taken place in Europe over the previous 40 years to establish ecological networks, primarily to combat fragmentation but also to deliver a range of other benefits to biodiversity at different geopolitical and spatial levels. In addition it places this work in the perspective of emerging EU policy on GI and considers how the concept has now been broadened to better reflect the integration of economic and social factors and the delivery of a range of ecosystem services. 


\section{Ecological Networks - Lessons Learned}

The concept of ecological networks is not new; the model has been developed over the past 35-40 years (beginning in the 1970s and 1980s in countries where a strong land use planning tradition had created the institutional environment for allocating functions at the landscape scale) in the context of increasingly fragmented European landscapes. The concept represents the translation of ecological knowledge about fragmentation processes in the landscapes of Europe and its consequences for populations of natural species into policy relevant information.

Originally, the main goal of ecological networks was to conserve biodiversity by maintaining and strengthening the integrity of ecological and environmental processes; and to counter the above effects by linking fragmented ecosystems with each other in order to promote exchange between populations of species and to enable the migration and spread of species. As a conservation approach, ecological networks are characterized by two generic objectives, namely: 1) maintaining the functioning of ecosystems as a means of facilitating the conservation of species and habitats; and, like GI, 2) promoting the sustainable use of natural resources in order to reduce the impacts of human activities on biodiversity and/or to increase the biodiversity value of man-managed landscapes [12].

The concept of ecological networks is implicit in a variety of international conventions (e.g. Ramsar Convention, Bern Convention), European agreements (Habitats and Birds Directives) and related policy implementation (Natura 2000 and Emerald Networks). It has now become operational in a number of national and European strategies [13]. The development of a European Ecological Network formed one of the priorities and activities of European nature conservation under the Pan-European Biological and Landscape Diversity Strategy (PEBLDS) which was endorsed by 54 European countries in Sofia, in 1995.

Ecological network maps and strategies have also been established at country level and around trans-boundary sites and site complexes. The Natura 2000 site network is now well developed across the European Union member states and the Emerald network constitution process is making progress at a pan-European level, particularly in the Western Balkans, Central and Eastern Europe, South Caucasus, as well as Norway and Switzerland [14]. Together with other networks of protected sites that stem from international, national or regional arrangements, they provide the basis for planning and joint action, and a backbone of GI across the European Continent. 
At regional and local level many planning authorities have applied the principles of ecological connectivity to spatial planning and strategies and these are the levels where actual implementation is now taking place., The latter have often included a significant level of stakeholder and public involvement and participation in the planning process.

While the PEEN served as an umbrella policy initiative, the elaboration of national level ecological networks provided a route towards more concrete implementation. In recent years several such projects have been implemented - including, perhaps most recently, the Macedonian National Ecological network (MAKNEN) [15].

An important lesson learned from the process of planning and implementing ecological networks, which will also be crucial for the success or failure of the GI approach, is that policy on its own does not deliver action on the ground unless supported by funding. PEBLDS, for example, was able to provide both financial and political support to the progress of the PEEN while at national level such work was often carried out with the support of project funding (e.g. Croatia - LIFE III, Macedonia - BBI Matra Fund).

However, national ecological networks are unlikely to function effectively unless they cross national boundaries. Many ecosystems, for instance in mountain ranges (the Alps, the Pyrenees, the Carpathians) and along river basins (the Rhine, the Danube), extend beyond national boundaries and are part of the EU's shared natural and cultural heritage and identity. There are already several good examples of cross boundary and regional ecological networks targeting these ecosystems (e.g. within the framework of the Alpine convention, Carpathian Convention, in the Dinaric Arc, European Green Belt, etc.). The new GI Strategy therefore looks at the possibility of developing a trans-European GI (TEN-G) initiative, similar to that already in place for large-scale EU transport (TEN-T) and energy (TEN-E) networks [16].

\section{Green Infrastructure - Future Perspective}

Whilst the term "Green Infrastructure" has in the past been used to describe natural, connected habitat within urban areas, with the launch of the EU 2020 European biodiversity headline target and 2050 vision [9], it has been taken forward by the European Commission as a much broader and much more complex concept which is emerging as a new and potentially influential policy instrument. In its Strategy and Roadmap to resource efficiency [17] the Commission also included a strategy on GI for which it received a mandate from the European Council and the European Parliament, "as a contribution 


\section{K. Civic and L. M. Jones-Walters}

to further integrating biodiversity considerations into other EU policies" [18]. Finally the GI Strategy was adopted on 6 May 2013 in the form of the Communication on "Green Infrastructure (GI) - Enhancing Europe's Natural Capital”.

The GI Strategy defines Green Infrastructure as: a strategically planned network of natural and semi-natural areas with other environmental features designed and managed to deliver a wide range of ecosystem services. It incorporates green spaces (or blue if aquatic ecosystems are concerned) and other physical features in terrestrial (including coastal) and marine areas. On land, GI is present in rural and urban settings.

The Strategy elaborates further that GI is a successfully tested tool for providing ecological, economic and social benefits through natural solutions. It helps us to understand the value of the benefits that nature provides to human society and to mobilise investments to sustain and enhance them. It also helps to avoid relying on infrastructure that is expensive to build when nature can often provide cheaper, more durable solutions. Many of these create local job opportunities. GI is based on the principle that protecting and enhancing nature and natural processes, and the many benefits human society gets from nature, are consciously integrated into spatial planning and territorial development. Compared to single-purpose, conventional infrastructure (also referred to as "grey" infrastructure), GI has many benefits. It is not a constraint on territorial development but promotes natural solutions if they are the best option. It can sometimes offer an alternative, or be complementary, to standard grey solutions [10].

It should be noted that the GI strategy is built on a number of different theoretical and conceptual starting-points in the fields of landscape ecology, conservation biology and nature protection. This results in the use of potentially inconsistent terminology which is perhaps inevitable when trying to combine different disciplines into a new single approach acceptable to practitioners from different backgrounds. However, it is generally accepted that GI includes the following elements [19]:

- Protected areas, such as Natura 2000 sites;

- Healthy ecosystems and area of high nature value outside protected areas such as floodplain areas, wetlands, coastal areas, natural forests etc...;

- Natural landscape features such small water courses, forest patches, hedgerows which can act as eco-corridors or stepping stones for wildlife;

- Restored habitat patches that have been created with specific species in mind e.g. to help expand the size of a protected area, increase 
foraging areas, breeding or resting for these species and assist in their migration/dispersal;

- Artificial features such as eco-ducts or eco-bridges, that are designed to assist species movement across insurmountable landscape barriers;

- Multifunctional zones where land uses that help maintain or restore healthy biodiverse ecosystems are favoured over other incompatible activities;

- Areas where measures are implemented to improve the general ecological quality and permeability of the landscape;

- Urban elements such as green parks, green walls and green roofs, hosting biodiversity and allowing for ecosystems to function and deliver their services by connecting urban, peri-urban and rural areas;

- Features for climate change adaptation and mitigation, such as marshes, floodplain forests and bogs - for flood prevention, water storage and $\mathrm{CO}_{2}$ intake, giving space to species to react to changed climate conditions.

As GI clearly still has some form of coherent ecological network at its core, it would seem prudent to take into account and build further on the work that has already been done at various geographical levels in order to define areas of existing and potential ecological connectivity. Below the level of ecological corridors that cross within and between countries, this includes the green and blue veining that makes up the patchwork quilt of traditionally managed multifunctional landscapes.

In many ways the lessons learned through the years of work on building ecological networks can and should be applied when thinking about GI as most of the issues remain the same. There is still a need to integrate the ecological network concept, which includes coherence and connectivity, into the development of GI, and equally into spatial and other infrastructure planning. Further, GI should also rely on existing policy instruments (such as the Natura 2000 and EU Water Framework Directive) which offer the potential for strengthening ecological networks to be exploited to the full in their implementation. Furthermore the EU Common Agricultural Policy presents an opportunity for new measures to be introduced that will benefit connectivity and contribute to making it a common practice to incorporate green infrastructure into the European agricultural landscapes. GI can make a significant contribution to the implementation of many of the EU's main policy objectives, especially in relation to regional and rural development, climate change, disaster risk management, agriculture and forestry [23, 24]. The new GI strategy advocates the full integration of a Green Infrastructure into these 


\section{K. Civic and L. M. Jones-Walters}

policies so that it becomes a standard component of territorial development across the EU.

The EU's main policies and their accompanying financial instruments will be vital for mobilising the potential of EU regions and cities to invest in GI. EU financed interventions can help to change the underlying paradigm from one where economy and environment are seen as trade-offs to one where the synergies and co-benefits are increasingly appreciated. They will also enable decision makers, stakeholders and civil society to achieve complex policy objectives such as regional and rural development, as well as water, resource efficiency and biodiversity goals whilst at the same time promoting new business opportunities for Small and Medium Enterprises (SMEs); for instance through the planning, implementation and monitoring of GI initiatives. [16].

The step that GI can take beyond what has already been achieved (with ecological networks) is to provide further context for informing the important decisions that need to be made in relation to the planning and management of the wider countryside outside of protected areas and other special sites. Thus, the further consideration of issues such as ecosystem services, climate change adaptation and ecological resilience are at the core of the GI approach [20].

An Expert Working Group on GI was set up by the European Commission to provide recommendations on what the EC work on GI should tackle from the view of stakeholders, Member States and scientists. During their work, the Working Group identified a number of benefits that GO can offer. According to these, GI should provide environmental, economic and social benefits, mainly by encouraging partnerships; and a crucial element in achieving this is the active involvement of relevant stake- and resource holders on the ground. It should continue to promote integrated spatial planning by identifying multifunctional zones and by incorporating habitat restoration measures and other connectivity elements into various land-use plans and policies. It should definitely be addressing the healthy-functioning of ecosystems, their protection and the provision and sustainable use of ecosystem goods and services, while increasing their resilience by addressing mitigation and adaptation to climate change. More specifically the ecosystem services it can provide include:

- It is an effective and cost-efficient tool for absorbing and sequestering atmospheric carbon dioxide $\left(\mathrm{CO}_{2}\right)$.

- It is contributing to the minimization of risks of natural disasters, by using ecosystem-based approaches for coastal protection through marshes/flood plain restoration rather than constructing dikes. 
- Efficient use of GI can reduce energy usage through passive heating and cooling; filtering air and water pollutants; decreasing solar heat gain; providing wildlife habitat; reducing the public cost of storm water management infrastructure and provide flood control; providing food sources; and stabilising soil to prevent or reduce erosion.

- It may contribute to landscape aesthetics, preservation of archaeological and cultural heritage, provision of accessible open spaces, sustainable transportation and energy, opportunities for environmental education and strengthen community sense for nature and quality of life [21].

Ecosystem services, and their contribution and value to human wellbeing, are now an important component of the modern policy agenda. However, there is also evidence that the condition of most services has decreased in last 50 years [25]. By strengthening and maintaining the good functioning of ecosystems, GI can promote the multiple delivery of ecosystem services. This applies equally to existing (semi)natural ecosystems, such as wetlands or floodplains, as well as to 'new' ecosystems, such as green roofs and vertical farms, and especially in relation to land that has been degraded and which often occurs in urban areas [7].

Ultimately, GI aims to contribute to the development of a more sustainable economy by investing in ecosystem-based approaches delivering multiple benefits, in addition to technical solutions, and mitigating adverse effects of transport and energy infrastructure. In other words the: “... ultimate aim (of GI) is to provide the framework for the territorial development of a green and low carbon economy" [20]. In many ways much of this was indeed the desired and intended objective for the future development of the ecological networks concept; leading to the conclusion that GI is a natural evolution of ecological networks. 'EUROPE 2020 - A strategy for smart, sustainable and inclusive growth' puts forward these three mutually reinforcing priorities which should, respectively, be based on: developing an economy based on knowledge and innovation; promoting sustainable growth through greater resource efficiency, greener and more competitive economies; and fostering high-employment economies for improved social and territorial cohesion. Sustainable growth means building a resource efficient, sustainable and competitive economy, exploiting Europe's leadership in the race to develop new processes and technologies, including green technologies, accelerating the roll out of smart information and communication technology grids, exploiting EU-scale networks, and reinforcing the competitive advantages of the EU. 


\section{K. Civic and L. M. Jones-Walters}

Linked to the Trans-European Networks (TENs) vision, key issues that can provide solid economic evidence include the scope to use GI thinking and measure GI contributions to resource efficiency across multiple objectives. Relevant here and to achieving important goals in such areas are two, out of seven, flagship initiatives set out in the Strategy; the "Innovation Union" which aims to:

- complete the European Research Area, to develop a strategic research agenda focused on challenges such as energy security, transport, climate change and resource efficiency, health and ageing, environmentallyfriendly production methods and land management, and to enhance joint programming with Member States and regions;

- improve framework conditions for business to innovate;

and a "Resource efficient Europe" flagship initiative which, among other things, aims to:

- mobilise EU financial instruments (e.g. rural development, structural funds, R\&D framework programme, TENs, European Investment Bank (EIB)) as part of a consistent funding strategy, that pulls together EU and national public and private funding;

- establish a vision of structural and technological changes required to move to a low carbon, resource efficient and climate resilient economy by 2050 which will allow the EU to achieve its emissions reduction and biodiversity targets [22].

\subsection{Green Infrastructure from a Stakeholders' Point of View}

Issues related to the implementation of GI were summarised nicely by the participants of the 'Greening European Regions Conference - biodiversity as a boost for regional and local economy' ${ }^{1}$ which took place in Oisterwijk, The Netherlands, on 12 December 2012. The main challenges and barriers for applying the GI approach and incorporating it into regional development, as envisaged by the participants, were threefold: 1) policy - lack of coordination between different levels of governance and between different sectors; 2) available resources - financial and human; and 3) awareness and knowledge among policy makers, stakeholders and the general public.

\footnotetext{
${ }^{1}$ The Conference was organised by ECNC and UNEP, the Province of Limburg, (B), and the municipality of Oisterwijk, in cooperation with the Province of Noord-Brabant (NL), the EU Committee of the Regions and ENCORE (http://www.regionsandbiodiversity.eu/node/10)
} 
When these were considered in more detail the main barriers identified were the following:

- Lack of policy coordination in decentralisation: while the general trend in policy making is decentralisation and giving more and more independence and responsibilities to the lower levels of governance (regional and local), there is often a lack of coordination between these different levels in setting the same or complementary priorities in order to make the implementation more effective.

- Integration and political agreement between different policy levels: there is often confusion about which level of governance is responsible for what, especially when it comes to planning - which is a key for the delivery of green infrastructure.

- Political commitment at all levels: there is often lack of firm political commitment towards the implementation of GI. Policy objectives often change with every new election and the consequent arrival of new politicians. This is the case at all levels: EU, national, regional and local.

- Lack of human and economic resources: GI based solutions are often long term projects which require ensuring long-term stable funding as well as qualified and knowledgeable teams of people; maintaining this in the long term can often represent a challenge.

- Lack of wish for GI: very often GI is a topic important to only a few people and therefore not a priority issue and not very high on the policy agenda; this is related to the low awareness of this issue amongst politicians and policymakers.

- Lack of knowledge (arguments): evidence based arguments should be available and used to show the benefits of GI to both decision-makers and the general public.

- Awareness is lacking: there is a need for raising awareness on the possibilities and benefits of a GI based approach among the relevant stakeholders (i.e. different sectors) and general public.

When discussing possible solutions for these issues some of the suggestions were:

- Involve stakeholders: relevant stakeholders should be involved in the implementation process in order to change their mind with proper arguments - it is often possible to agree on the common goals.

- EU Policies Coordination: could be a tool for coordination between different policy levels. 
- Demonstrate the explicit economic value of GI: such explicit examples (including definitive economic figures) should be used to assist in briefing and convincing politicians of the effectiveness of the approach.

- Find innovative solutions: GI based solutions should not be more expensive than 'grey' infrastructure solutions; this requires a certain level of innovation. Once identified, such solutions should be promoted.

- Use more local/regional examples when communicating to stakeholders: it is much easier for people to relate to the area they are familiar with.

- Public - private commitment is a good approach towards implementation of GI: a number of such examples already exist and these should be used to learn from and promote the approach further.

A number of these suggestions have in the meantime been picked up and are being followed up by the European Commission in their actions to facilitate the deployment of GI across the EU member states.

\section{Conclusions}

The contribution of ecological networks, and subsequently, GI to the provision of ecosystem services, transition to a more resource efficient economy and to mitigation and adaptation in relation to the effects of climate change are important areas for research and subsequent articulation into policy. Quantifying the economic benefits of ecological networks and GI and making them explicit through interdisciplinary research is also a clear necessity looking into the social, economic and ecological mechanisms, as well as at the maintenance of biodiversity and the ecological services they provide.

Further work can be carried out in relation to the full translation of the protected area networks into functional ecological networks and making them integral building blocks of the GI both at the level of policy and practice. In addition information about how to create actual ecological networks at the delivery level, particularly where this has involved stakeholder and public participation needs to be researched and made widely available. Knowledge transfer is needed as well as new knowledge especially in relation to the impact of changing environmental and land use conditions on species and habitats in the wider countryside.

Leadership has already been mentioned in the context of who has responsibility for ecological networks at European, regional, national and local levels. Issues remain the same when we are talking about GI. Linked to this is the 
issue of communication; specifically to politicians and decision makers within key sectors (such as spatial planning, transport, industry, etc.) but more widely to researchers, conservation practitioners, businesses and the interested public [1].

As a new policy concept, GI sets ambitious goals to bridge the gap between the different sectors and to integrate benefits for biodiversity with those for socio-economic interests, to improve delivery of ecosystem services, climate change mitigation and, more than that, it aims to promote innovative solutions and the use of same land for multiple purposes. However, it is still somewhat unclear how all of this will be achieved and the European Commission, supported by scientists and environmental NGOs, is therefore currently placing a particular emphasis on providing guidance documents to demonstrate the benefits of GI for different sectors. A subsequent challenge will be to measure success in the short to medium term through the development of appropriate indicators.

\section{References}

[1] Jones-Walters, L. and Čivic, K., Draft Action Plan on the future strategic development of the Pan-European Ecological Network (PEEN) for the period 2012-2020. Council of Europe, T-PVS/PA (2012) 12, 2012.

[2] EEA, Landscape fragmentation in Europe. EEA Report No 2/2011, Joint EEA-FOEN report, 2011.

[3] Jongman R.H.G., Bouwma I.M., Griffioen A., Jones-Walters L. and Van Doorn A.M., The Pan European Ecological Network: PEEN, Landscape Ecology 26: 311-326, 2011.

[4] Council of Europe, $3^{\text {rd }}$ meeting Report. T-PVS/PA (2011) 13. Convention on the conservation of European wildlife and natural habitats, Group of Experts on Protected Areas and Ecological Networks, Sept. 2011.

[5] Council Directive 92/43/EEC on the conservation of natural habitats and of wild fauna and flora, Official Journal L 206, 22/07/1992 P. 0007-0050, May 1992.

[6] Directive 2009/147/EEC of the European Parliament and of the Council on the conservation of wild birds (codified version of Directive 79/409/EEC), Official Journal L 20, 26/01/2010 P. 0007-0025, Nov. 2009.

[7] European Commission, The Multifunctionality of Green Infrastructure, In-depth report. Science for Environment Policy, 2012. 
[8] Convention on Biological Diversity, Aichi Biodiversity Targets. TARGET 11 - Technical Rationale extended (provided in document COP/10/INF/12/Rev.1), 2010.

[9] European Commission, Our life insurance, our natural capital: an EU biodiversity strategy to 2020. Communication from the Commission to the European Parliament, the Council, the Economic and Social Committee and the Committee of the Regions. COM(2011) 244 final, 2011.

[10] European Commission, Green Infrastructure (GI) - Enhancing Europe's Natural Capital, COM/2013/0249 final, May 2013.

[11] Pan-European Biological and Landscape Diversity Strategy, PanEuropean 2020 Strategy For Biodiversity. 13th Meeting of the Council for the Pan-European Biological and Landscape Diversity Strategy, STRA-CO (2011) 2, 2011.

[12] Bennett, G. and Wit, P., The Development and Application of Ecological Networks: a Review of Proposals, Plans and Programmes. Amsterdam: AIDEnvironment, 2001. In: Snethlage, M., L. Jones-Walters (Eds.), Interactions between policy concerning spatial planning policy and ecological networks in Europe (SPEN - Spatial Planning and Ecological Networks). ECNC, Tilburg, the Netherlands, 2008.

[13] Jongman, R.H.G., Külvik, M and Kristiansen. I., European ecological networks and greenways. Landscape and Urban Planning, 68:305-319, 2004.

[14] Council of Europe, Final data summary of the Joint EU/CoE Programme on the setting-up of the Emerald network. T-PVS/PA (2012) 4. Convention on the conservation of European wildlife and natural habitats, Group of Experts on Protected Areas and Ecological Networks, 2012.

[15] Brajanoska R., K. Čivic, K., Hristovski, S., Jones-Walters, L., Levkov, Z., Melovski, Lj., Melovski, D. and Velevski, M., Background document on Ecological Networks - Project: Development of the National Ecological Network in FYR Macedonia (MAK-NEN), MES, Skopje, Republic of Macedonia; ECNC, Tilburg, the Netherlands, 2009.

[16] European Commission, Building a Green Infrastructure for Europe, 2013.

[17] European Commission, Roadmap to a Resource Efficient Europe. $\operatorname{COM}(2011) 571$ final, 2011.

[18] Council of the European Union, EU Biodiversity Strategy to 2020 Council conclusions, 2011.

[19] European Commission, Green Infrastructure Fact Sheet, 2010. 
[20] Jones-Walters, L. and Čivic, K., Ecological Networks and green infrastructure. In Ferdinandova, V. (ed.), EU Environmental Policies and Strategies in South-Eastern Europe - Training guidelines for involving CSOs from SEE in implementation of EU nature-related legislation IUCN, Belgrade, Serbia, 14-35, 2012.

[21] Green Infrastructure Working Group of the European Commission, Recommendations, Nov. 2011.

[22] European Commission, Communication from the Commission: EUROPE 2020 - A strategy for smart, sustainable and inclusive growth, COM(2010) 2020, March 2010.

[23] European Commission, Guidelines on Climate Change and Natura 2000, 2013.

[24] Naumann, S., Anzaldua, G., Berry, P., Burch, S., Davis, M., Frelih-Larsen, A., Gerdes, H. and Sanders, M., Assessment of the potential of ecosystembased approaches to climate change adaptation and mitigation in Europe, Final report to the European Commission, DG Environment, Contract no. 070307/2010/580412/SER/B2, Ecologic institute and Environmental Change Institute, Oxford University Centre for the Environment, November 2011.

[25] Carpenter, S.R., Mooney, H.A., Capistrano, A.J. et al., Science for managing ecosystem services: beyond the Millenium Ecosystem Assessment, Proceedings of national Academy of Science USA 106:1305-1312, 2009.

\section{Biographies}

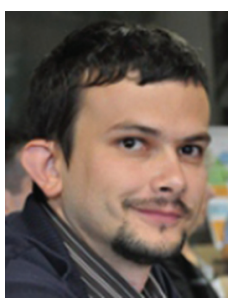

Kristijan Čivić is Senior Project Manager at ECNC in the Programme Area Green Infrastructure. His main responsibilities are development and implementation of project proposals in the field of ecological networks, Natura 2000 and Green Infrastructure. He is also a licensed workshop facilitator and has a significant experience in preparing and giving training sessions on stakeholder involvement and participatory action planning. He has worked 
in nature conservation policy and practice for more than 10 years. Prior to joining ECNC, Kristijan worked for five years at the State Institute for Nature Protection in Croatia, a government agency that delivers expertise and knowledge to the relevant ministry responsible for nature conservation. As such he has experience of project management, national and international policies and regulations regarding nature conservation. He participated in the process of establishing the National Ecological Network in Croatia. He worked on several international projects in South-East Europe related to ecological networks and stakeholder involvement.

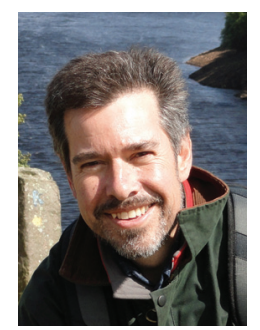

Lawrence Jones-Walters is presently Head of Biodiversity and Policy at Alterra and has held a number of senior roles, most recently Deputy Executive Director ECNC-European Centre for Nature Conservation (2007-2013). He has worked in nature conservation policy and practice and sustainability for nearly 30 years and has extensive experience of national and international project and programme management (Europe, Asia and North America). His long experience in the science policy arena includes work with the Council of Europe (Group of Expert on Protected Areas and Ecological Networks), UNEP, the European Commission, the European Environment Agency and the European Topic Centre - Biodiversity. He is a regular contributor to international forums, conferences and journals; including contributing to the development of the international policy agenda, for example, in relation to ecological networks and green infrastructure. He has expertise in a range of areas, for example, he has been involved in the 'Streamlining European 2010 Biodiversity Indicators' (SEBI2010) process and its successor; and the European Topic Centre for Biodiversity (he currently chairs the Management Committee of the Topic Centre); and is co-author of the EEA report (2012) on European Protected Areas: past, present and future. He has also worked as an expert providing input to the environmental component of the Eurostat headline indicators for sustainable development. He has experience in sustainable development, ecosystem services and business and biodiversity and 
Implementing Green Infrastructure and Ecological Networks in Europe 323

has worked in regional economic development towards the achievement of environmental integration into the sustainable development agenda (including work with business and industry, SMEs, social inclusion and health issues). He gained his $\mathrm{PhD}$ in conservation management, has a MSc in Applied Entomology, an MBA, and has an extensive publications list. 
